3. Methods for the recovery of gallium from its ferrocyanide in the presence of zinc have been described.

New Haven, Cons.

[CONTRIBUTION FROM THE KENT CHEMICAL LABORATORY OF YALE UNIVERSITY.]

\title{
THE QUALITATIVE SEPARATION AND DETECTION OF URANIUM, VANADIUM AND CHROMIUM WHEN PRESENT TOGETHER.
}

By Philip E. Browning.

Received October 30, 1920.

A. A. Noyes and his associates in their excellent treatise on a System of Qualitative Analysis, which includes some of the less common elements, give the following procedure for the separation of uranium, vanadium and chromium when present together. ${ }^{1}$ To the solution containing sodium chromate, sodium vanadate, and the double sodium-uranium carbonate nitric acid is first added to neutrality and then in slight excess and the chromium is precipitated as lead chromate by lead nitrate. After the removal of the lead chromate by filtration the excess of lead is removed by hydrogen sulfide and the lead sulfide filtered off. The excess of hydrogen sulfide is removed by boiling, re-oxidation effected by bromine, the excess of bromine removed by boiling, and after acidification with acetic acid, the uranium is precipitated by sodium phosphate. The presence of uranium is confirmed by dissolving the precipitate in hydrochloric acid, adding sodium chloride and treating with potassium ferrocyanide. The filtrate from the uranium phosphate is made alkaline with ammonium hydroxide and saturated with hydrogen sulfide, a pink or violet color indicating oxysulfide of vanadium, if that element is present.

The work to be described is a modification of the above method involving the use of another reaction and obviating the necessity of the introduction and subsequent removal of lead.

The solution containing chromic and vanadic acids together with a uranium salt is made faintly alkaline with ammonia and then faintly acid with acetic acid and treated with ammonium phosphate. This precipitates the phosphate of uranium which is filtered off and washed. If the filtration is difficult it may be successfully accomplished by the introduction of some shredded filter paper. The precipitate on the filter paper is treated with an acidified solution of potassium ferrocyanide and if uranium is present a characteristic red-brown stain is the result. The filtrate is then treated with sulfurous acid in distinct excess, which reduces the chromic and vanadic acids and the excess of the sulfurous acid is removed by boiling. This solution is then treated with bromine water in distinct excess and the excess of bromine is removed by boiling. The bromine oxidizes the vanadium to the acid condition and does not affect

\footnotetext{
1 'This Jolrnai, 3o, 481 (1908).
} 
the reduced chromiuth. During the boiling to remove the excess of bromine some of the chromium is precipitated as the phosphate, and the precipitation may be made complete by the addition of ammonia in faint excess and the removal of the excess by boiling. A green precipitate indicates chromium. After the removal of the chromium by filtration the filtrate is made alkaline with ammonia and saturated with hydrogen sulfide, which gives the pink or violet oxysulfide of vanadium if that element is present.

'The results are given in the table. Solutions were prepared containing one $\mathrm{mg}$. of $\mathrm{V}_{2} \mathrm{O}_{5}$ and $\mathrm{UO}_{2}{ }^{1}$ to a cc. and $10 \mathrm{mg}$. of $\mathrm{CrO}_{3}$ to a cc. 'The initial volume in every case was $15 \mathrm{cc}$. when the ammonium phosphate was added, the solution reached a volume of about $50 \mathrm{cc}$. when the chromium was precipitated, and it was concentrated to about $20 \mathrm{cc}$. before saturation with hydrogen sulfide.

TABDEL I.

\begin{tabular}{|c|c|c|c|c|c|c|}
\hline & $\begin{array}{c}\mathrm{CrO}_{3} \\
\text { present. } \\
\mathrm{G} .\end{array}$ & $\begin{array}{l}\mathrm{UO}_{2} \\
\text { present. } \\
\text { G. }\end{array}$ & $\begin{array}{c}\mathrm{V}_{2} \mathrm{O}_{5} \\
\text { present. } \\
\mathrm{G} .\end{array}$ & $\begin{array}{l}\text { Test for } \\
\mathrm{CrO}_{8} \text {. }\end{array}$ & $\begin{array}{l}\text { Test for } \\
\mathrm{UO}_{2} \text {. }\end{array}$ & $\begin{array}{l}\text { Test for } \\
\mathrm{V}_{2} \mathrm{O}_{3} \text {. }\end{array}$ \\
\hline (1) ..... & $\ldots$ & 0.001 & & $\ldots \ldots \ldots$ & Distinct & $\ldots$ \\
\hline$(2) \ldots \ldots$ & $\ldots$ & $\ldots$ & 0.0005 & & 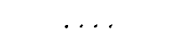 & Distinct \\
\hline (3) & 0.100 & 0.001 & 0.001 & Heavy ppt. & Distinct & Distinet \\
\hline (4). & 0.100 & 0.001 & 0.001 & Heavy ppt. & Distinct & Distinct \\
\hline (5)....... & $\ldots$ & 0.001 & 0.010 & $\cdots$ & Distinct & Strong \\
\hline (6) ..... & $\cdots$ & 0.010 & 0.001 & $\ldots \ldots \ldots$ & Strong & Distinct \\
\hline (7) $\ldots \ldots$ & 0.100 & & . & Heavy ppt. & 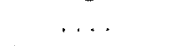 & $\cdots$ \\
\hline (8) ..... & 0.001 & 0.100 & 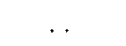 & Faint green ppt & Heavy ppt. & $\ldots$ \\
\hline (9) $\ldots \ldots$ & & 0.100 & . & Faint white ${ }^{a}$ ppt. & Heavy ppt. & $\ldots$ \\
\hline$(10) \ldots$ & 0.001 & $\cdots$ & 0.010 & Green ppt. & $\ldots$ & Strong \\
\hline
\end{tabular}

[Contribution from the Chemistry Department of Columbia University, No. 348. AND THE JACISSON LABORATORY, E. I. DU PONT DE NEMOURS AND COMPANY.]

THE VISCOSITY OF LIQUIDS. V. THE IDEALITY OF THE SYSTEM: BENZENE-BENZYL BENZOATE AND THE VALIDITY OF THE BINGHAM FLUIDITY FORMULA.

\author{
By James Kendali and KenNeth PotTer Monroe. \\ Received November 15, 1920.
}

Introduction.

The viscosity curve of the above system at $25^{\circ}$ was carefully determined by $u^{2}$ in 1917 , and the experimental results were shown to agree closely with the empirical formula: $\eta^{1 / 3}=a \eta_{1}^{1 / 3}+b \eta_{2}^{1 / 3}$ (where $\eta$ is the viscosity of a mixture; $\eta_{1}$ and $\eta_{2}$ the viscosities of the 2 components; $a$ and $b$ the mol. fractions of the 2 components in the mixture). The maximum divergence between calculated and observed values was only

1 The radical uranyl, not the oxide.

: Kendall and Monroe, Thrs Journal, 39, 1787 (1917). 